\title{
Энергия связи пластин кремния и сапфира при повышенных температурах соединения
}

\author{
(С) И.Е. Тысченко, Э.Д. Жанаев, В.П. Попов
}

Институт фризики полупроводников им. А.В. Ржанова, Сибирского отделения Российской академии наук, 630090 Новосибирск, Россия

E-mail: tys@isp.nsc.ru

(Получена 19 марта 2018 г. Принята к печати 29 марта 2018 г.)

Изучены гидрофильность поверхности и энергия связи пластин кремния и сапфира при температуре соединения $50^{\circ} \mathrm{C}$. Установлено, что нагрев пластин $\mathrm{Si}$ и $\mathrm{Al}_{2} \mathrm{O}_{3}$ до $50^{\circ} \mathrm{C}$ сопровождается ростом степени гидрофильности их поверхностей. Эффект объясняется улучшением степени чистоты поверхности за счет десорбции примесных атомов в вакуум и увеличением плотности оборванных связей. Обнаружен рост энергии связи пластин кремния и сапфира при температуре соединения $50^{\circ} \mathrm{C}$ и последующем нагреве в интервале $100-250^{\circ} \mathrm{C}$ по сравнению с ее значениями при соединении при комнатной температуре. Определена энергия активации роста энергии связи, которая составила 0.57 эВ.

DOI: 10.21883/FTP.2019.01.46989.8867

\section{1. Введение}

Структуры кремний-на-сапфире (КНС) являются основой для создания радиационностойких цифровых и аналоговых СБИС высокочастотного диапазона для применения в радиоэлектронной аппаратуре [1]. По сравнению со структурами кремний-на-изоляторе, выполненными на подложках объемного кремния, КНС структуры обладают рядом преимуществ, которые обусловлены свойствами сапфира, самого твердого из оксидов, сохранящего свои качества при высоких температурах, имеющего хорошие теплофизические свойства и превосходную прозрачность. Он химически устойчив ко многим кислотам и щелочам при температурах вплоть до $1000^{\circ} \mathrm{C}$. Эти свойства обусловливают широкое применение сапфира в агрессивных средах, когда требуется оптическая прозрачность в диапазоне от видимого до ближнего ИК диапазона энергетического спектра (0.17-5.5 мкм). Применение сапфира в качестве подложек в кремниевой технологии связано в первую очередь с его высокими изолирующими свойствами (удельное сопротивление составляет $10^{11}-10^{16} \mathrm{OM} \cdot \mathrm{cm}$ ) и, как следствие, с очень низкой паразитной емкостью. Это обеспечивает увеличение быстродействия приборов на его основе, а также низкую потребляемую мощность, лучшую линейность вольт-амперных характеристик и бо́льшую изоляцию элементов интегральных схем, по сравнению с кремниевыми подложками. КНС структуры обладают высокой радиационной стойкостью: до $10^{8}$ рад при $\gamma$-облучении и до $10^{12}$ рад при облучении протонами. В КНС структурах может быть реализовано достижение теоретического предела рабочей частоты МОП-транзистора до 500 ГГц.

Основной проблемой при создании структур КНС является рассогласование решеток кремния и сапфира, которое составляет около $24 \%$. Это является причиной большой плотности дефектов в пленках кремния, созданных методом газофазной эпитаксии, который был впер- вые использован для создания КНС структур [2]. Универсальным методом соединения пластин без привлечения каких-либо вспомогательных склеивающих средств является метод прямого сращивания [3]. Основным его достоинством является пригодность для соединения атомарно гладких плоскостей различных материалов, независимо от их ориентации и рассогласования решеток. При этом граница раздела между соединяемыми материалами также получается атомарно-гладкой. Соединение происходит при низких температурах. Однако основным препятствием для дальнейшего использования КНС структур, созданных этим методом, является большое различие в коэффициентах теплового расширения кремния и сапфира (в $\sim 2.9$ раза), которое может быть причиной большого содержания дефектов в пленке кремния при ее термическом отколе имплантированным водородом, а при последующем высокотемпературном отжиге приводить к расслоению и растрескиванию перенесенной пленки. Релаксация напряжений, возникающих в этом случае, может быть достигнута за счет уменьшения толщины слоя кремния до долей микрометра [4]. В частности, было показано, что с уменьшением толщины слоя кремния до значений $d<0.01 D$, где $d-$ толщина слоя кремния, а $D$ - толщина слоя сапфира, в пластине сапфира напряжения практически отсутствуют, а в пленке кремния их распределение становится однородным по толщине [4]. Задача создания тонкопленочных высокосовершенных КНС слоев может быть решена в рамках метода водородно-индуцированного переноса пленок кремния на сапфировую подложку $[5,6]$.

Необходимым условием $100 \%$ переноса слоя $\mathrm{Si}$ на подложку $\mathrm{Al}_{2} \mathrm{O}_{3}$ является обеспечение большой энергии связи указанных поверхностей. Согласно имеющимся в литературе данным, энергия связи соединенных пластин возрастает по мере увеличения температуры отжига [7]. При этом начальная энергия связи может также увеличиваться с ростом времени соединения. В работе [7] методом раскрытия разлома было установлено, что для 
пары поверхностей кремний-сапфир начальная энергия связи относительно высока и при изменении времени выдержки соединенных пластин при температуре отжига $100-200^{\circ} \mathrm{C}$ может увеличиться от 0.2 до 0.7 Дж/ $\mathrm{m}^{2}$.

В данной работе с целью уменышения относительного термоупругого напряжения пластин кремния и сапфира и обеспечения их $100 \%$ соединения были изучены энергии связи поверхностей $\mathrm{Si}$ и $\mathrm{Al}_{2} \mathrm{O}_{3}$ при повышенных температурах соединения.

\section{2. Методика экспериментов}

В экспериментах использовались пластины кремния диаметром 100 мм $p$-типа проводимости с ориентацией (100) производства WRS (США) и $\mathrm{Al}_{2} \mathrm{O}_{3}$ с ориентацией (0001) производства завода „Монокристалл“. Нагрев и соединение пластин кремния и сапфира проводились в установке сращивания SUSS MicroTech SB8e. Перед нагревом и соединением пластины проходили стандартную химическую обработку. Пластины сапфира проходили обработку в $\mathrm{NH}_{3}(25 \%): \mathrm{H}_{2} \mathrm{O}_{2}(30-31 \%): \mathrm{H}_{2} \mathrm{O}=1: 1: 5$ при комнатной температуре. Пластины кремния подвергались химической обработке в $\mathrm{NH}_{3} \quad(25 \%): \mathrm{H}_{2} \mathrm{O}_{2}$ $(30-31 \%): \mathrm{H}_{2} \mathrm{O}=1: 4: 60$, промывке в деионизованной воде, сушке. В ряде экспериментов поверхность пластин дополнительно подвергалась травлению в кислородной плазме в течение 30-240 с при мощности плазмы 36-42 Вт. После обработки в плазме пластины сапфира подвергались обработке в 100\% изопропиловом спирте, в 5\% изопропиловом спирте и промывке в деионизованной воде. Пластины кремния обрабатывались в $\mathrm{HCl}$ $(37 \%): \mathrm{H}_{2} \mathrm{O}_{2}(30-31 \%): \mathrm{H}_{2} \mathrm{O}=1: 1: 5$ при температуре $80^{\circ} \mathrm{C}$, промывались в деионизованной воде и в $\mathrm{NH}_{3}$ $(25 \%): \mathrm{H}_{2} \mathrm{O}_{2}(30-31 \%): \mathrm{H}_{2} \mathrm{O}=1: 1: 5$ при температуре $80^{\circ} \mathrm{C}$. Такие обработки формировали гидрофильные поверхности пары пластин.

Одним из методов оценки чистоты поверхности пластины является определение ее степени гидрофильности. Этот метод основан на использовании явления смачиваемости поверхности каплей жидкости [8]. В наших экспериментах степень гидрофильности поверхностей определялась по величине контактного угла (угла смачиваемости) между каплей деионизованной воды объемом 20 мкл и поверхностью кремния. Объем капли задавался с помощью дозатора. Шероховатость поверхности исследовалась методом атомно-силовой микроскопии.

Перед соединением пластины нагревались в вакууме до температуры $50^{\circ} \mathrm{C}$. При этом пластина кремния находилась на расстоянии 1 мм от пластины сапфира. Затем пластины попарно соединялись и температура повышалась до $100-250^{\circ} \mathrm{C}$. При указанных температурах пластины выдерживались в течение 5, 10 или 15 мин. Измерение энергии связи поверхностей кремния и сапфира измерялось методом раскрытия разлома $[9,10]$. После соединения пластин и соответствующих термообработок между соединенными поверхностями вдвигалось лезвие длиной $3.7 \mathrm{~cm}$ и толщиной 100 мкм до тех пор, пока не формировался прямой фронт разлома. Затем проводились измерение расстояния от фронтальной линии разлома до края лезвия и расчет энергии связи.

\section{3. Результаты и обсуждение}

На рис. 1 представлены изображения поверхностей пластин кремния (рис. $1, a)$ и сапфира (рис. 1,b) диаметром 100 мм после соответствующих химических обработок и нагрева до температуры около $50^{\circ} \mathrm{C}$ в течение 5 мин с нанесенными на них каплями воды объемом 20 мкл. Из рисунка видно, что капли имеют правильную круглую форму, а их средний диаметр составляет 1.4 и 0.9 см для поверхностей кремния и сапфира соответственно. Увеличение длительности выдержки пластин при температуре $50^{\circ} \mathrm{C}$ до 15 мин привело к тому, что на поверхности кремния капли незначительно растекаются и их средний размер составляет $1.8 \mathrm{~cm}$, а на поверхности сапфира размер капли даже незначительно сократился

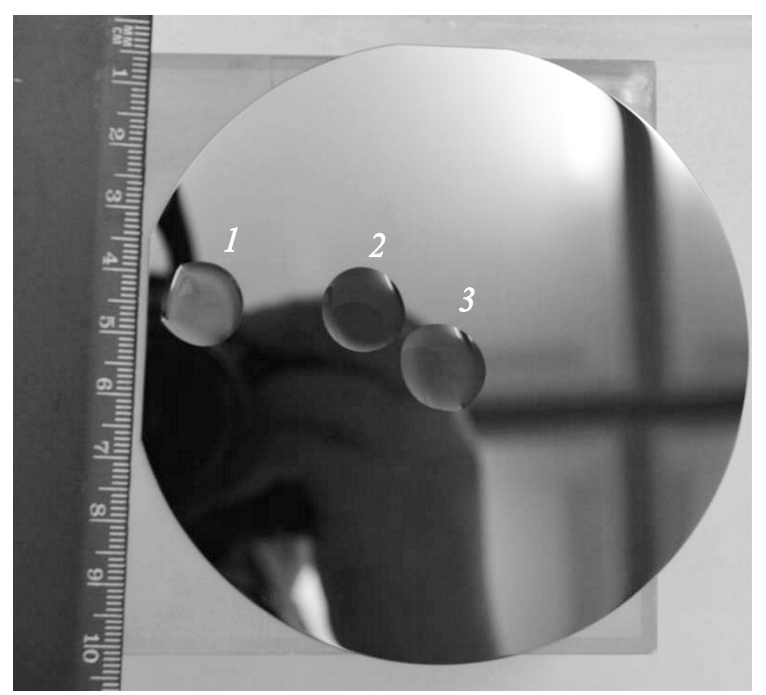

$a$

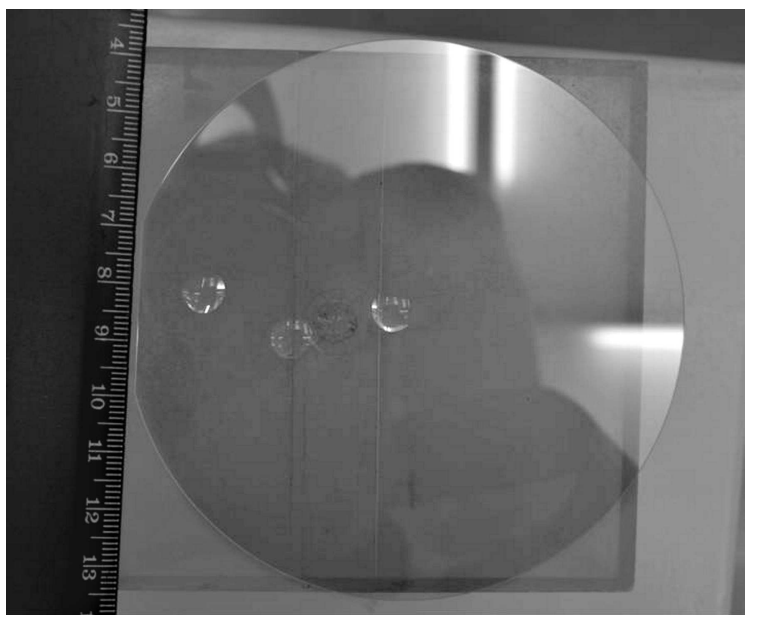

$b$

Рис. 1. Изображение поверхностей кремния $(a)$ и сапфира $(b)$, нагретых до $T=50^{\circ} \mathrm{C}$ в течение 5 мин, с нанесенными каплями деионизованной воды объемом 20 мкл. 
$a$
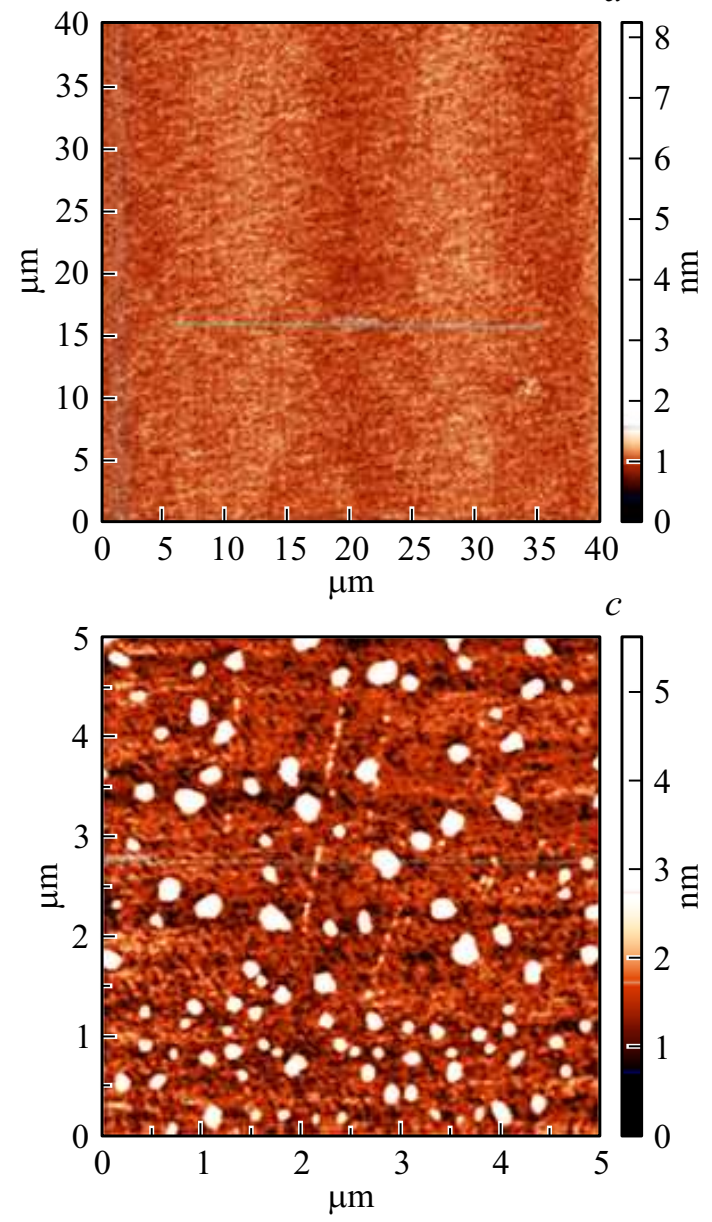
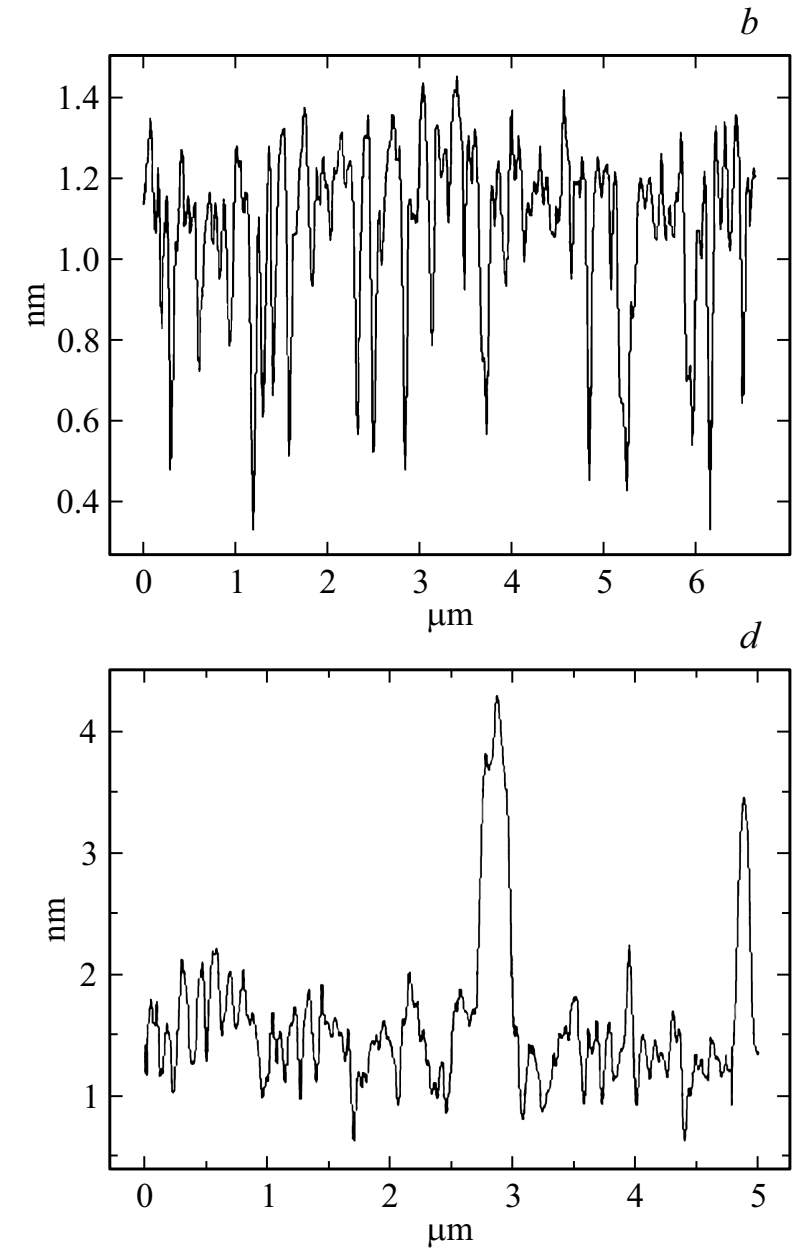

Рис. 2. Изображение рельефа $(a, c)$ поверхности пластины сапфира и изменение шероховатости поверхности $(b, d)$ в растре размером $40 \times 40$ мкм $^{2}(a, b)$ и $5 \times 5$ мкм $^{2}(c, d)$.

и составил около $0.8 \mathrm{~cm}$. При этом размеры капель до нагрева составляли около 1.3 и 0.7 см для кремния и сапфира соответственно.

Степень гидрофильности поверхностей кремния и сапфира в зависимости от времени выдержки при температуре соединения $50^{\circ} \mathrm{C}$ определялась из расчета угла смачиваемости следующим образом:

$$
\cos \Theta=\left((d / 2)^{2}-h^{2}\right) /\left((d / 2)^{2}+h^{2}\right),
$$

где $\Theta-$ угол смачиваемости поверхности, $d-$ диаметр капли раствора на поверхности, $h \approx \sqrt{2 V / \pi d}-$ высота капли воды на поверхности, $V-$ объем капли. В соответствии с выражением (1) величина угла смачиваемости исходной поверхности кремния каплей воды составляла $15.4^{\circ}$ (табл. 1). После нагрева пластины до температуры $50^{\circ} \mathrm{C}$ и выдержки в течение 5 мин его величина несколько увеличилась и составила $17.2^{\circ}$. Увеличение времени прогрева до 15 мин привело к улучшению степени гидрофильности поверхности кремния, увеличению размера капли и соответствующему уменьшению угла смачиваемости до $9.9^{\circ}$. В случае поверхности пластины сапфира углы смачиваемости составили 51, 29 и $35^{\circ}$ для исходной пластины кремния, а также после прогрева при температуре $50^{\circ} \mathrm{C}$ в течение 5 и 15 мин соответственно (табл. 2). Растекание капли на поверхности определяется энергией связи молекул воды и кремния либо сапфира. Эксперименты показывают, что умеренный нагрев как пластины кремния, так и сапфира до $50^{\circ} \mathrm{C}$ приводит к увеличению гидрофильности их поверхностей, что может быть связано с улучшением их чистоты за счет десорбции примесных атомов и увеличения плотности оборванных связей. В случае поверхности сапфира степень гидрофильности остается ниже по сравнению со степенью гидрофильности поверхности кремния. Причины наблюдаемых различий гидрофильности поверхностей кремния и сапфира могут быть связаны как с разной исходной их шероховатостью, так и с разной скоростью испарения избыточных углеводородов при указанной температуре.

На рис. 2 представлены $(a)$ изображение рельефа поверхности пластины сапфира в растре размером $40 \times 40$ мкм $^{2}$ и $(b)$ изменение шероховатости пластины на выбранном участке вдоль линии, показанной на рис. 2,a. В этом случае средняя шероховатость по 
Таблица 1. Параметры нагрева, диаметр капель воды и угла смачиваемости поверхности пластин кремния

\begin{tabular}{c|c|c|c|c}
\hline № & $\begin{array}{c}\text { Температура, } \\
\text { нагрева, }{ }^{\circ} \mathrm{C}\end{array}$ & $\begin{array}{c}\text { Время нагрева, } \\
\text { мин }\end{array}$ & $\begin{array}{c}\text { Диаметр } \\
\text { капли, см }\end{array}$ & $\begin{array}{c}\text { Угол } \Theta, \\
\text { град. }\end{array}$ \\
\hline 1 & 0 & 0 & 1.4 & 15.4 \\
2 & 50 & 5 & 1.3 & 17.2 \\
3 & 50 & 15 & 1.9 & 9.9
\end{tabular}

Таблица 2. Параметры нагрева, диаметр капель воды и угла смачиваемости поверхности пластин сапфира

\begin{tabular}{c|c|c|c|c}
\hline № & $\begin{array}{c}\text { Температура, } \\
\text { нагрева, }{ }^{\circ} \mathrm{C}\end{array}$ & $\begin{array}{c}\text { Время нагрева, } \\
\text { мин }\end{array}$ & $\begin{array}{c}\text { Диаметр } \\
\text { капли, см }\end{array}$ & $\begin{array}{c}\text { Угол } \Theta, \\
\text { град. }\end{array}$ \\
\hline 1 & 0 & 0 & 0.6 & 51 \\
2 & 50 & 5 & 0.9 & 29 \\
3 & 50 & 15 & 0.8 & 35
\end{tabular}

пластине вдоль выбранного участка составляла 0.12 нм, а среднеквадратичная шероховатость - 0.16 нм. Уменьшение окна растра до величины $20 \times 20$ мкм $^{2}$ не приводит к существенным изменениям этих значений. Более подробный анализ поверхности пластины сапфира позволили сделать исследования шероховатости в окне растра размером $5 \times 5$ мкм $^{2}$ (рис. $2, c$ и $d$ ). В растре размером $5 \times 5$ мкм $^{2}$ средняя шероховатость по пластине увеличивается до $0.16 \mathrm{HM}$, а среднеквадратичная шероховатость до 0.23 нм. Среднеквадратичная шероховатость поверхности пластин кремния была не хуже 0.1 нм. Дополнительная обработка поверхности кремния в кислородной плазме не привела к существенному изменению степени ее гидрофильности по сравнению с прогревом при температуре $50^{\circ} \mathrm{C}$. Наоборот, дополнительная обработка в кислородной плазме поверхности сапфира приводит к существенному увеличению ее гидрофильности. Размер капли при этом увеличивается в $\sim 3$ раза, а угол смачиваемости становится равным его значению на поверхности кремния.

Увеличение степени гидрофильности поверхностей при повышенной температуре может быть также свидетельством атомных перестроек на самой поверхности. Это в свою очередь может сказаться и на энергии связи между соответствующими соединенными поверхностями. Изучение энергии связи пластин кремния и сапфира при температуре соединения $50^{\circ} \mathrm{C}$ проводилось методом раскрытия разлома в зависимости от температуры нагрева после соединения (рис. 3). Энергия связи рассчитывалась по формуле [3]

$$
\gamma=\left(\gamma_{1}+\gamma_{2}\right) / 2=\left(3 y^{2} E_{1} d_{1}^{3} E_{2} d_{2}^{3}\right) / 16 L^{4}\left(E_{1} d_{1}^{3}+E_{2} d_{2}^{3}\right),
$$

где $\gamma$ - энергия связи поверхностей кремния и сапфира, $\gamma_{1}-$ энергия связи поверхностей кремния, $\gamma_{2}-$ энергия связи поверхностей сапфира,

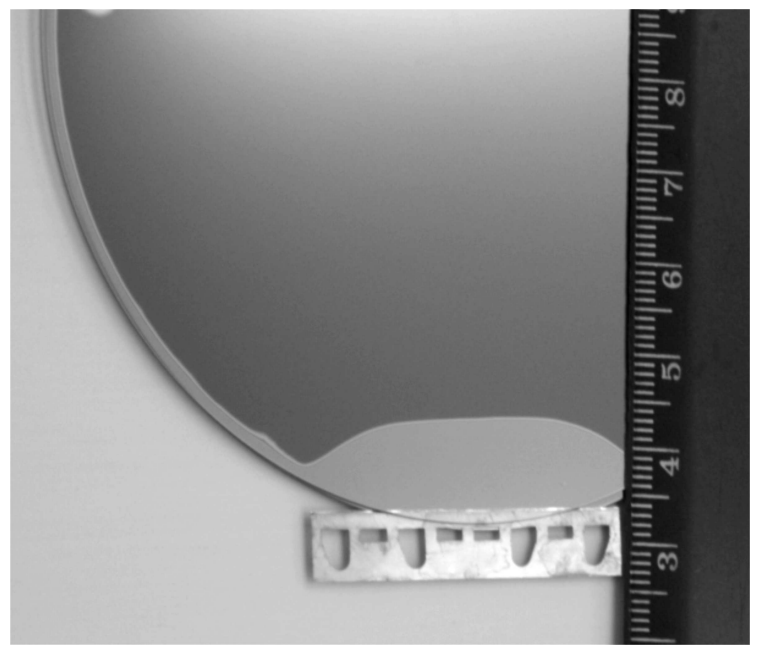

Рис. 3. Фотографическое изображение раскрытия разлома КНС пластины, созданной прямым соединением пластин $\mathrm{Si}$ и $\mathrm{Al}_{2} \mathrm{O}_{3}$, нагретых при $T=50^{\circ} \mathrm{C}$, после соединения и дополнительного нагрева при $T=200^{\circ} \mathrm{C}$ в течение 10 мин.

$E_{1}=1.09 \cdot 10^{11} \mathrm{H} / \mathrm{M}^{2}$ - объемный модуль Юнга кремния, $E_{2}=3.35 \cdot 10^{11} \mathrm{H} / \mathrm{M}^{2}$ - объемный модуль Юнга сапфира, $d_{1}=525$ мкм - толщина пластины кремния, $d_{2}=500$ мкм - толщина пластины сапфира, $y=100$ мкм - толщина лезвия, $L-$ расстояние от фронтальной линии разлома до края лезвия. С ростом температуры отжига соединенных пластин в течение 10 мин энергия связи увеличивалась. Так, после отжига при температуре $100^{\circ} \mathrm{C}$ она составляла около 0.6 Дж/ $\mathrm{m}^{2}$. Это приблизительно соответствует ранее полученному значению поверхностной энергии пластин кремния и сапфира, соединенных при комнатной температуре и выдержанных в течение 500 ч или после коротковременного отжига при температурах 100 и $200^{\circ} \mathrm{C}$ [7]. Увеличение температуры отжига до $200^{\circ} \mathrm{C}$ в наших экспериментах приводило к росту поверхностной энергии до 1.9 Дж/м². Такая энергия связи пластин, соединенных при комнатной температуре, в работе [7] достигалась лишь после отжига при температуре $200^{\circ} \mathrm{C}$ в течение нескольких десятков часов. Зависимость энергии связи пластин $\mathrm{Si}$ и $\mathrm{Al}_{2} \mathrm{O}_{3}$ от обратной температуры нагрева после их соединения при температуре $50^{\circ} \mathrm{C}$ представлена на рис. 4. Энергия активации, с которой происходит рост поверхностной энергии, была рассчитана по наклону этой зависимости и составила 0.57 эВ. Полученное значение энергии активации в указанном температурном интервале может быть связано с десорбцией водорода и полимеризацией связей, включающих атомы кислорода на границе сращивания поверхностей кремния и сапфира. В пользу этого механизма указывают и данные по увеличению степени гидрофильности поверхности сапфира после обработки в кислородной плазме. Однако установление механизма увеличения энергии связи пластин кремния и сапфира за счет их 


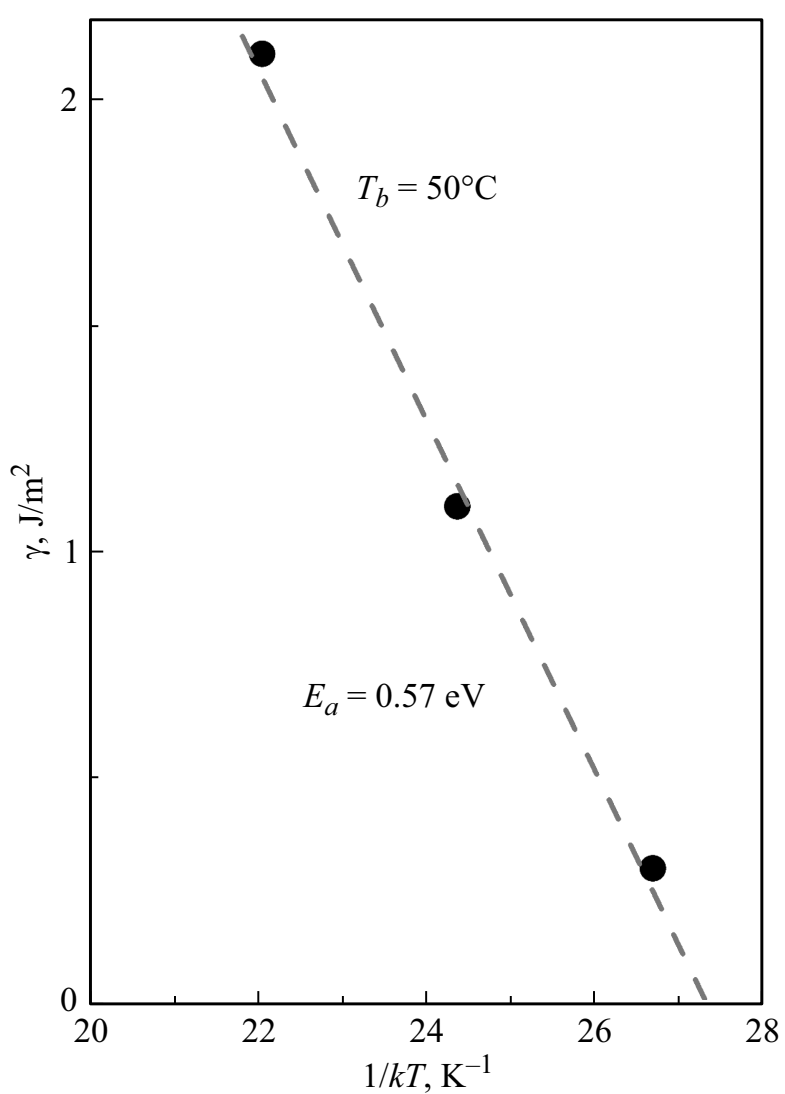

Рис. 4. Зависимость энергии связи пластин кремния и сапфира, соединенных при температуре $50^{\circ} \mathrm{C}$ после прогрева в течение 10 мин, в зависимости от обратной температуры последующего отжига в вакууме.

предварительного нагрева требует дальнейших подробных исследований.

\section{4. Заключение}

Изучены гидрофильность поверхности и энергия связи пластин кремния и сапфира при температуре соединения $50^{\circ} \mathrm{C}$. Установлено, что нагрев пластин перед соединением до $50^{\circ} \mathrm{C}$ приводит к росту их степени гидрофильности. Эффект объясняется улучшением чистоты поверхности за счет десорбции примесных атомов и увеличением количества оборванных связей. Обнаружено, что увеличение температуры соединения до $50^{\circ} \mathrm{C}$ сопровождается ростом энергии связи пластин кремния и сапфира при последующем отжиге в интервале от 100 до $250^{\circ} \mathrm{C}$ по сравнению с известными литературными данными, полученными при соединении пластин, находящихся при комнатной температуре. В указанном температурном интервале энергия активации роста энергии связи составляет 0.57 эВ. Десорбция водорода и полимеризация связей с участием атомов кислорода на границе сращивания поверхностей $\mathrm{Si}$ и $\mathrm{Al}_{2} \mathrm{O}_{3}$ рассматриваются в качестве возможных механизмов, обеспечивающих полученное значение энергии активации.

\section{Список литературы}

[1] V.M. Stuchebnikov. J. Commun. Technol. Electron., 50, 622 (2005).

[2] H.M. Manasevit, W.L. Simpson. J. Appl. Phys., 35, 1349 (1964).

[3] Q.-Y. Tong, U. Gösele. Semiconductor wafer bonding (Ins. John Wiley and Sons Inc., 1999).

[4] D.M. Jefkins. J. Phys. D: Appl. Phys., 3, 770 (1970).

[5] R. Meyer, O. Kononchuk, H. Moriceau, M. Lemiti, M. Bruel. Solid State Electron., 115 (pt B), 225 (2016).

[6] В.П. Попов, Э.Д. Жанаев, Н.В. Дудченко, В.А. Антонов, А.И. Попов. Патент РФ № 2538352. Заявитель и патентообладатель Новосибирск, ИФП СО РАН, № 2013126847/(039881). [Бюл. № 1 (2015)].

[7] P. Kopperschmidt, G. Kästner, D. Hesse, N. . Zakharov, U. Gösele. Appl. Phys. Lett., 70, 2972 (1997).

[8] А. Адамсон. Физическая химия поверхностей, под ред. 3.М. Зорина, В.М. Муллера (М., Мир, 1979).

[9] P.P. Gillis, J.J. Gilman. J. Appl. Phys., 35, 647 (1964).

[10] W.P. Maszara, G. Goetz, A. Caviglia. J.B. McKitterick. J. Appl. Phys., 64, 4843 (1988).

Редактор Г.А. Оганесян

\section{Bonding energy of silicon and sapphire wafers under elevated contact temperature}

\section{I.E. Tyschenko, E.D. Zhanaev, V.P. Popov}

Rzhanov Institute of Semiconductor Physics, Siberian Branch of Russian Academy of Sciences, 630090 Novosibirsk, Russia

\begin{abstract}
The hydrofilicity and the surface energy of silicon and sapphire pairs under the contact temperature $50^{\circ} \mathrm{C}$ were studied. It was detected that the wafer pre-heating to $50^{\circ} \mathrm{C}$ resulted in the surface hydrofility growth. The effect was explained in frame of the surface purity because of impurity atoms desorption and of respective increasing the dangling bond density. An increase in the contact temperature to $50^{\circ} \mathrm{C}$ was accompanied with the surface energy growth of silicon and sapphire pairs during subsequent bonding heating from in the region $100-250^{\circ} \mathrm{C}$ as compared with that obtained elsewhere from the room-temperature contacted pairs. At that, the activation energy of the surface energy growth was $0.57 \mathrm{eV}$. Both hydrogen desorption and the oxygen provided bond polymerization at the interface between the $\mathrm{Si}$ and $\mathrm{Al}_{2} \mathrm{O}_{3}$ surfaces are considered as possible mechanisms provided the obtained activation energy.
\end{abstract}

